\title{
USE OF RECENT GEOID MODELS TO ESTIMATE MEAN DYNAMIC TOPOGRAPHY AND GEOSTROPHIC CURRENTS IN SOUTH ATLANTIC AND BRAZIL MALVINAS CONFLUENCE
}

\author{
Alexandre Bernardino Lopes ${ }^{1 *}$ and Joseph Harari ${ }^{2}$ \\ ${ }^{1}$ Universidade Federal do Pampa - Campus Itaqui \\ (Rua Luiz Joaquim de Sá Brito, s/n - 97650-000 Itaqui, RS, Brasil) \\ ${ }^{2}$ Universidade de São Paulo, Instituto Oceanográfico \\ (Praça do Oceanográfico, 191, 05508-120 São Paulo, SP, Brasil) \\ Suporte Financeiro: CNPq - Conselho Nacional de Desenvolvimento Científico e Tecnológico
}

*Corresponding author: ablopesbjo@sgponline.com.br

\section{A B S T R ACT}

The use of geoid models to estimate the Mean Dynamic Topography was stimulated with the launching of the GRACE satellite system, since its models present unprecedented precision and space-time resolution. In the present study, besides the DNSC08 mean sea level model, the following geoid models were used with the objective of computing the MDTs: EGM96, EIGEN-5C and EGM2008. In the method adopted, geostrophic currents for the South Atlantic were computed based on the MDTs. In this study it was found that the degree and order of the geoid models affect the determination of TDM and currents directly. The presence of noise in the MDT requires the use of efficient filtering techniques, such as the filter based on Singular Spectrum Analysis, which presents significant advantages in relation to conventional filters. Geostrophic currents resulting from geoid models were compared with the HYCOM hydrodynamic numerical model. In conclusion, results show that MDTs and respective geostrophic currents calculated with EIGEN-5C and EGM2008 models are similar to the results of the numerical model, especially regarding the main large scale features such as boundary currents and the retroflection at the Brazil-Malvinas Confluence.

\section{RESUMO}

A utilização de modelos geoidais na determinação da Topografia Dinâmica Média foi impulsionada com o lançamento dos satélites do sistema GRACE, já que seus modelos apresentam precisão e resolução espacial e temporal sem precedentes. No presente trabalho, além do modelo de nível médio do mar DNSC08, foram utilizados os seguintes modelos geoidais com o objetivo de calcular as TDMs: EGM96, EIGEN-5C e EGM2008. No método adotado, foram calculadas as respectivas correntes geostróficas para o Atlântico Sul a partir das TDMs. O grau e ordem dos modelos geoidais influenciam diretamente na determinação da TDM e correntes. Neste trabalho verificou-se que presença de ruídos da TDM requer a utilização de técnicas de filtragem eficientes, como o filtro baseado em Singular Spectrum Analysis, que apresenta vantagens significativas em relação aos filtros convencionais. As correntes geostróficas resultantes dos modelos geoidais foram comparadas com resultados de modelo numérico hidrodinâmico HYCOM. Como principais conclusões, os resultados mostraram que as TDMs e respectivas correntes geostróficas calculadas com os modelos EIGEN-5C e EGM2008 foram similares aos resultados do modelo numérico, especialmente em relação às principais feições de grande escala, como as correntes do contorno e a retroflexão na Confluência Brasil Malvinas.

Descriptors: Dynamic Topography, Geoid Models, Geostrophic Currents.

Descritores: Topografia Dinâmica, Modelos Geoidais, Correntes Geostróficas.

\section{INTRODUCTION}

The difference between mean sea level (MSL) and geoid is called Mean Dynamic Topography (MDT), whose determination is of great importance in the study and interpretation of hydrodynamic and geophysical phenomena, such as the absolute geostrophic circulation. MSL models are accurate and reliable. However, efforts are currently concentrated on the determination of precise, noiseless geoid models, with suitable spatial resolution for the study of short wavelength variabilities of the ocean circulation. 
Up to satellite launch of Gravity Recovery and Climate Experiment System (GRACE), the assimilation of geoid heights in the ocean had been carried out only in a few cases, due to the low precision and resolution of the geoid models. At present, the use of a reference surface defined by a geoid model is justified by recent advances in determining geopotential models, as Tapley et al. (2005) pointed out in the evaluation of first GRACE models. The previous of GRACE geoid models had $1000 \mathrm{~km}$ of resolution, and they were used only in large-scale studies, such as subtropical gyres. The low resolution of these models disabled their full use, once important aspects of the ocean circulation have wavelengths between 100 and $200 \mathrm{~km}$ (RIO; HERNANDEZ, 2004).

The first geopotential models came with the first artificial satellite launch, in 1957, where precise observations of satellite movements allowed determining coefficients of low degree development of geopotential series (determination of long wavelengths). Since then, geoid models have been improved in order to solve short wavelengths.

OSO91A geopotential model (RAPP et al., 1991), developed by Ohio State University (OSU) from terrestrial gravity data and satellite observations, is extended up to 360 level. This model was incorporated to TOPEX/Poseidon data. However, its precision (standard deviation of approximately $26 \mathrm{~cm}$ ) is not satisfactory. New surface gravity data besides satellite orbit and altimetry data were incorporated in the development of Earth Gravitational Model 1996 (EGM96), obtaining considerable improvement in relation to OSO91A model. EGM96 model was incorporated to Jason satellite altimeter data. However, its error (standard deviation of approximately $18 \mathrm{~cm}$, according to Lemoine et al., 1998) is still high for many oceanographic applications.

Recently, global models of gravity fields were released in EIGEN-5C (FÖRSTE et al., 2008) and EGM2008 (PAVLIS et al., 2008). The EIGEN$5 \mathrm{C}$, complete up to 360 degree and order, is a result of GRACE system, Laser Geodynamics Satellite (LAGEOS) and surface data. EGM2008 was recently published by U.S. National Geospatial-Intelligence Agency (NGA) and is complete up to 2159 degree and order in terms of spherical harmonic coefficients. These models, together with MSL DNSC08 model (ANDERSEN; KNUDSEN, 2008), were used and evaluated in this publication. On March, 2009, Ocean Circulation Explorer (GOCE) system was launched. This system should significantly improve the precision of the reference system defined by geoid models ( 1 to $2 \mathrm{~cm}$ ) and consequently support ocean currents and heat transport studies.

Despite many improvements from recent geoid models (in terms of precision and resolution), resulting MDTs present noise that has come mainly from the respective models. Vianna et al. (2007), by using GGM02C geoid model and MSL GSFCMSS00 model, proposed a filter based on Singular Spectrum Analysis (SSA), whose methodology was efficient for noise removal. This methodology was adapted in the present paper.

Aiming at comparing MDTs and correspondent geostrophic currents, HYCOM hydrodynamic numerical model outputs were used, namely the sea level elevations and currents (BLECK, 2002).

Consequently, the objectives of this study are: (1) to determine MDTs and Geostrophic Surface Currents (GSC) by using SSA filter applied to EGM2008, EIGEN-5C and EGM96 geoid models (computed with the respective harmonic coefficients); and (2) to evaluate and compare the obtained results with hydrodynamic numerical model results for the South Atlantic, showing the main differences and the evolution of the geoid models.

\section{MDT Determination, Filtering and Geostrophic Surface Currents \\ MDTs and Geoid Models.}

MDT, determined from MSL and geoid models, is given by:

$M D T=M S S-N$

where MSS (in here, DNSC08) is the mean sea level, and $N$ is the expanded geoid height, given by the spherical harmonic sum (WAHR et al., 1998):

$$
\begin{aligned}
& N(\theta, \varphi)=a \sum_{l} \sum_{m} P_{l m}\left(\cos (\theta)\left(C_{l m} \cos (m \varphi)+S_{l m} \operatorname{sen}(m \varphi)\right)\right. \\
& l=0 \rightarrow \infty \\
& m=0 \rightarrow l
\end{aligned}
$$

where $a$ is the major semi-axis of reference ellipsoid, $\theta$ is the co-latitude, $\varphi$ is the longitude, $C_{l m}$ and $S_{l m}$ are the coefficients of the expansion and $P_{l m}(\cos (\theta))$ are the associated Legendre functions of degree and order $m$.

Coefficients of EGM96 and EIGEN-5C models are complete up to 360 degree and order, and EGM2008 model up to 2159 degree and order. Geoid models were computed taking into account the mean tide system and reference ellipsoid, similar to altimeter satellites TOPEX/Poseidon (AVISO, 1996) and Jason (DESAI et al., 2003). Ellipsoid parameters are: $f$ flattening $=1 / 298.257$ and $a$ major semi-axis= $6378136.3 \mathrm{~m}$. 


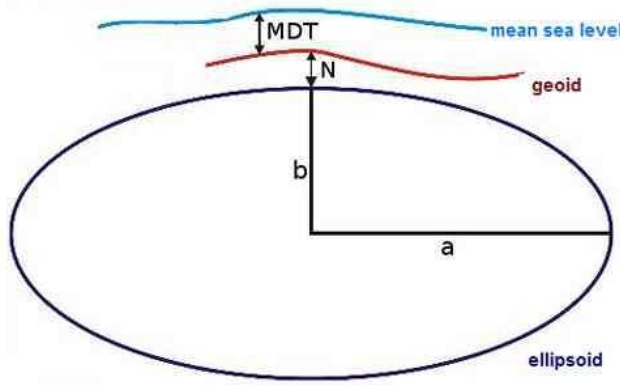

Fig. 1. Reference system for Mean Dynamic Topography (MDT), considering the reference ellipsoid (with a, b semiaxes), geoid (N) and mean sea level (MSL).

Three MDT models were computed, with resolution of $0.5^{\circ} \mathrm{x} \quad 0.5^{\circ}:$ MDT_EGM96, MDT_EIGEN-5C and MDT_EGM2008, which correspond to the differences between DNSC08 mean sea level and EGM96, EIGEN-5C and EGM2008 geoid models, respectively as (1) and (2).

With filtered MDTs (represented by $\eta$ ), absolute Surface Geostrophic Currents (SGC) ( $u$ and $v$ components, to east and north, respectively) can be easily estimated by:

$u=-(g / 2 \Omega \sin \varphi) /(\partial \eta / \partial y)$

$v=(g / 2 \Omega \sin \varphi) /(\partial \eta / \partial x)$

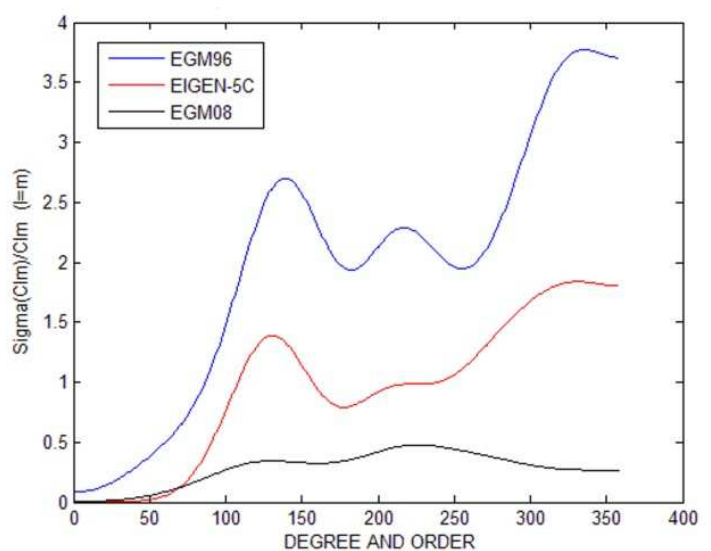

where $(2 \Omega \sin \varphi)$ is Coriolis parameter $(f), \Omega$ is Earth's angular velocity, $\varphi$ is the latitude, $g$ is the gravity acceleration, $(\partial \eta / \partial x)$ is the zonal MDT variation, $(\partial \eta / \partial y)$ is the meridional MDT variation, being $\partial x$ and $\partial y$ spacings equal to $0.5^{\circ}$.

\section{Resolution and Error of Geoid Models}

Approximate resolution of a geoid model is equivalent to $20000 \mathrm{~km} / l_{\max }$, where $l_{\max }$ is the maximum degree of the model (SWENSON; WARH, 2002). Consequently, the model with higher resolution is EGM2008 (9 $\mathrm{km})$; considering this expression, EGM96 and EIGEN-5C models have resolution of approximately $55 \mathrm{~km}$. However, in practice, resolution depends on the considered data gravity distribution and quality. Despite EIGEN-5C resolution is equal to EGM96 one, the precision of harmonic coefficients should be observed. Figure 2 shows the relationship between errors of coefficients and harmonic coefficients for $l=m$.

The relation between error and coefficient is directly proportional to the degree and order of the model, on the other hand, coefficients of degree and order higher than 50 have amplitudes of 1e-10, making the errors higher than the coefficient in some cases (Fig. 2). The precision of geoid models directly reflects the precision of the coefficients. Thus, geoid models with high degree and order present noise that has to be properly removed; in long wavelengths, geoid models are precise but they have low resolution. As shown in above figure, EGM2008 model, truncated in 360 degree and order, has lower error than EIGEN5C and EGM96.

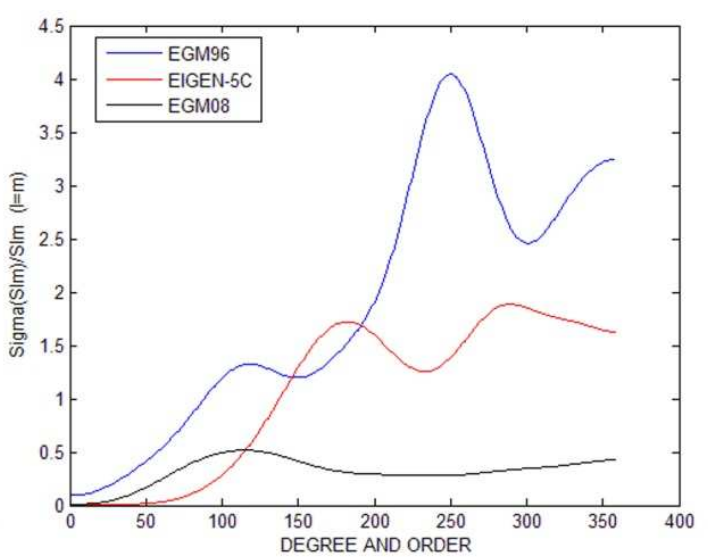

Fig. 2. Relations between coefficient errors and coefficients, depending on $S_{\mathrm{lm}}$ (left) and $\mathrm{C}_{\mathrm{lm}}$ (right) harmonics (for $\mathrm{l}=\mathrm{m}$ ). 
SSA Filter

As previously mentioned, noise is one of the major problems in the use of existing geoid models for MDT determination, especially for models expanded with high degree and order. SSA was first used as a MDT filtering method by Vianna et al. (2007), since this technique had only been applied in time series reconstitutions as well as filling of gaps due to the lack of information (KONDRASHOV; GHIL, 2006).

This study applied SSA technique exposed in Ghil et al. (2002). The filter depends on the choice of covariance matrix dimension $(\mathrm{MxM})$, which is directly proportional to the number of constituents to be considered in the signal reconstitution. In this work, the best result was obtained with $\mathrm{M}=3$ and reconstructed series explain more than $90 \%$ of the signal variance.

In the MDT case, filtering procedure consists of two steps: first, meridional noise is removed, and then, zonal noise is removed, starting from filtered data in step 1. In these two steps the same filter origin is applied.

As it can be seen in Figure 3, filter application is efficient in removing noise. Other advantages of this filter are the easy application in boundary regions, and the possibility of using with small data sets, by controlling the matrix dimension M.

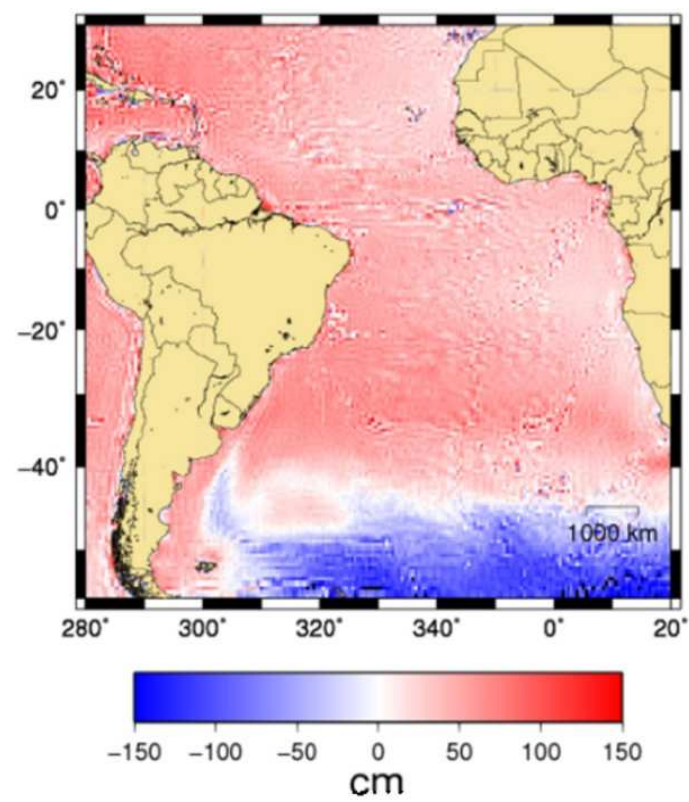

Hydrodynamic Numerical Model HYCOM

The Hybrid Coordinate Ocean Model (HYCOM) is a numerical model based on isopycnic coordinates in the open and stratified ocean, reverting slowly to sigma coordinates in coastal and shelf regions, and linear coordinates in very shallow or homogeneous sea. The model presents thus an optimized vertical coordinate system, representing an improvement over other models (BLECK, 2002).

\section{RESULTS}

Dynamic Topography computed with EGM2008 model

The degree and order of a geoid model directly affect the determination of the dynamic topography (and consequently the respective computed currents) because they are directly related to its resolution. In order to evaluate this relationship three models of MDT were used, based on EGM2008 model, truncated to degree and order 2159,360 and 120, respectively. As can be seen in Figure 4, the degree and order of the model change the features of MDT.



Fig. 3. Comparison between unfiltered (left side) and filtered (right side) MDT_EGM2008. 

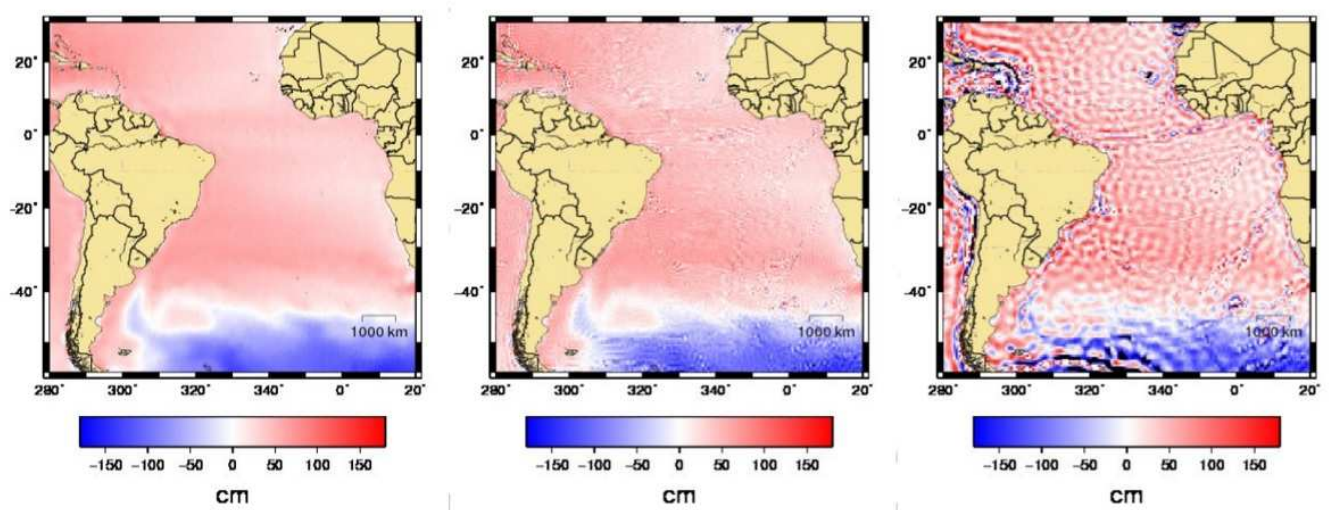

Fig. 4. Dynamic topography computed with EGM2008 geoidal model truncated at 120 (left) 360 (center) and 2159 (right) degree and order.

The MDT model truncated to maximum degree shows better results; when the model was determined in 360 degree and order, some noise was observed in the MDT, even without changes of the large and meso-scale features; however, in degree and order 120 , the noise practically do not allow the geostrophic currents computation.

\section{Resulting Geostrophic Currents}

Brazil Malvinas Confluence (BMC) is characterized by the convergence of Brazil Current (BC) with Malvinas Current (MC). Circulation features determined with the hydrodynamic numerical model and with MDTEGM08 are similar to the circulation patterns shown by Reid (1989) and Stramma and England (1999) in the first $140 \mathrm{~m}$ of the water column (Fig. 5). When using MDT_EIGEN-5C, the same pattern was observed but with remarkable differences in $\mathrm{MC}$ retroflection region $\left(\sim 40^{\circ} \mathrm{S}\right)$; however, it should be taken into account that this model was calculated with degree and order 360 , while EGM2008 used degree and order 2159. Current patterns determined with MDT_EGM96 present different results, even the MC retroflection was not observed near latitude $40^{\circ} \mathrm{S}$ (Fig. 5), but that might be justified by the low precision and resolution of the model geoid.

Statistical comparison for South Atlantic is shown in Table 1, with MDT_EGM08 model currents having higher correlation and lower error, when computing the mean of the square root error (SQRE) in relation HYCOM outputs. On the other hand, MDT_EGM96 model currents present the lowest correlation and largest error.

Table 1. Statistical comparison (average of all grid points) of elevations (MDT) and currents components (UM, VM) between the results of numerical hydrodynamic HYCOM model and geoid models.

\begin{tabular}{|l|l|l|l|l|l|l|l|l|l|}
\hline \multirow{2}{*}{} & \multicolumn{3}{|c|}{ EGM2008 } & \multicolumn{3}{c|}{ EIGEN-5C } & \multicolumn{3}{c|}{ EGM96 } \\
\cline { 2 - 10 } & MDT & UM & VM & MDT & UM & VM & MDT & UM & VM \\
\hline Correlation & 0.79 & 0.62 & 0.69 & 0.76 & 0.62 & 0.64 & 0.46 & 0.10 & 0.11 \\
\hline SQRE & $0.10 \mathrm{~m}$ & $0.06 \mathrm{~m} / \mathrm{s}$ & $0.07 \mathrm{~m} / \mathrm{s}$ & $0.12 \mathrm{~m}$ & $0.09 \mathrm{~m} / \mathrm{s}$ & $0.12 \mathrm{~m} / \mathrm{s}$ & $0.23 \mathrm{~m}$ & $0.12 \mathrm{~m} / \mathrm{s}$ & $0.16 \mathrm{~m} / \mathrm{s}$ \\
\hline
\end{tabular}


a

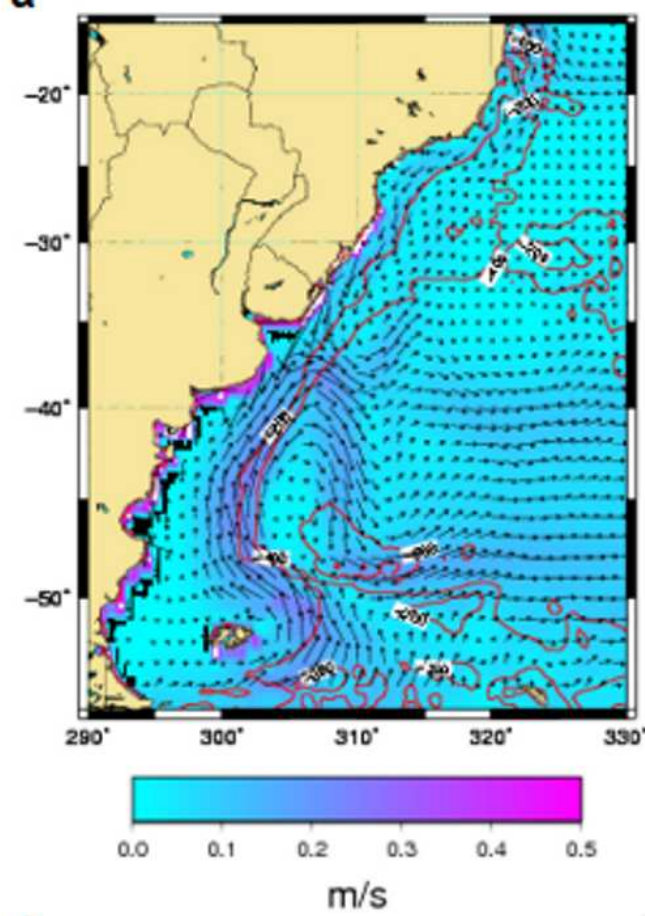

C

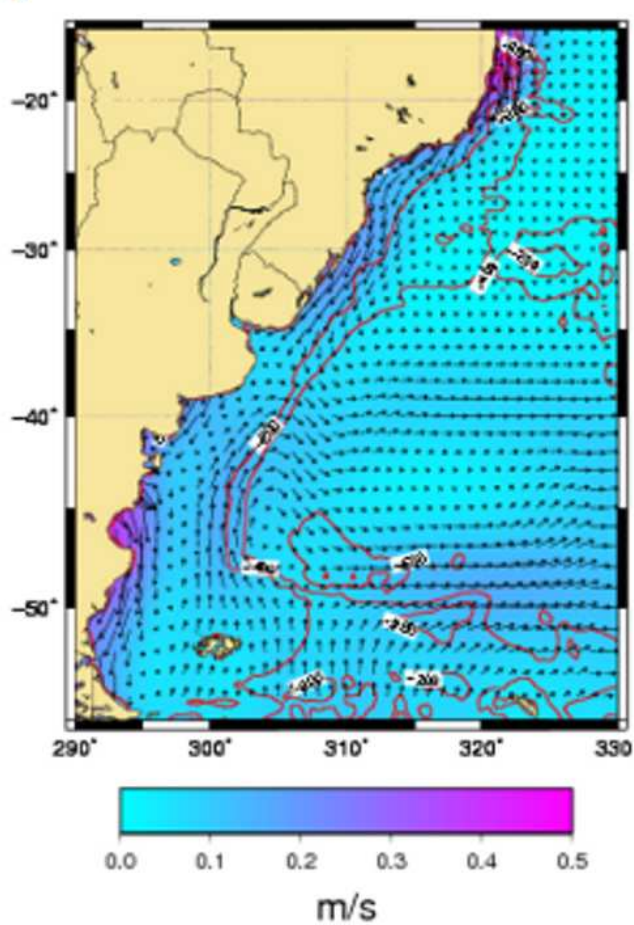

b

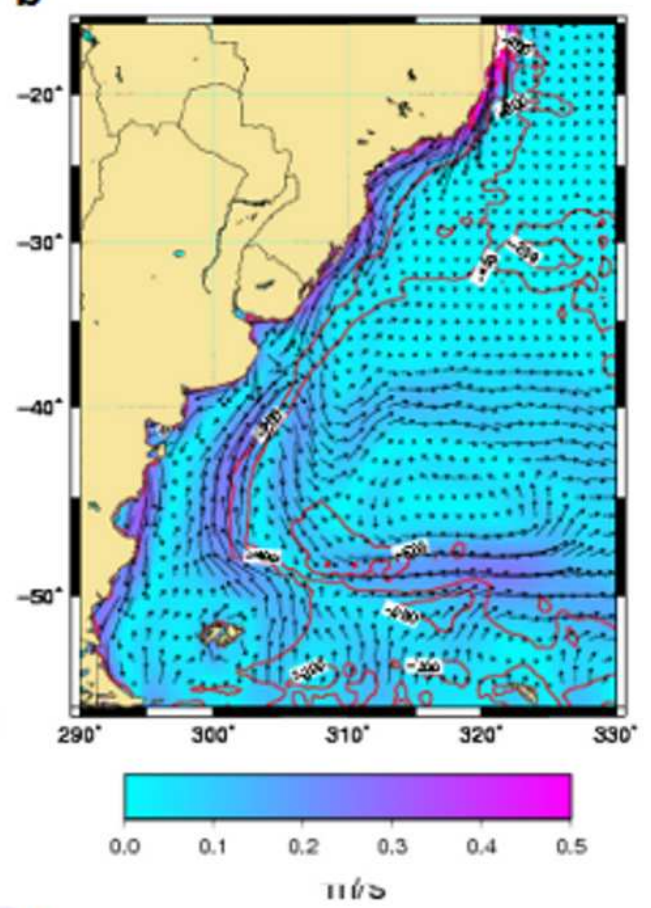

d

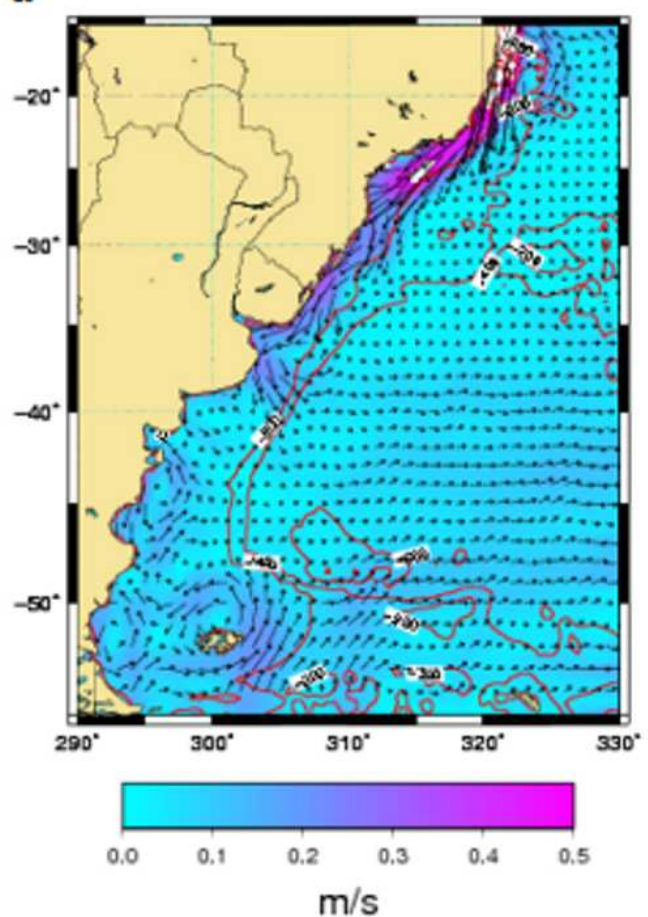

Fig. 5. Surface geostrophic currents in MC and BC regions determined with: (a) HYCOM, (b) MDT_EGM08, (c) EIGEN-5C and (d) EGM96. 
$\mathrm{BC}\left(20^{\circ} \mathrm{S}-30^{\circ} \mathrm{S}\right)$ in $200 \mathrm{~m}$ isobath was well characterized in all models, with resulting velocities of approximately $0.15 \mathrm{~m} / \mathrm{s}$ when determined with MDTEGM2008, $0.17 \mathrm{~m} / \mathrm{s}$ by using MDT_EIGEN-5C, and $0.30 \mathrm{~m} / \mathrm{s}$ considering MDT_EGM96; the hydrodynamic numerical model provided velocity of $0.16 \mathrm{~m} / \mathrm{s}$ in the same region. These values, except MDT_EGM96 currents, are close to those found by Müller at al. (1998), with moored instruments in the World Ocean Circulation Experiment (WOCE), located at $23^{\circ} \mathrm{S}$ latitude, in isobath of $210 \mathrm{~m}$, with recorded values average of $0.15 \mathrm{~m} / \mathrm{s}$. However, the value found with MDT_EGM96 is consistent with Böebel et al. (1999), who found in BC velocities of $0.30 \mathrm{~m} / \mathrm{s}$ by using floating buoys.

\section{Conclusions}

Comparison of EGM96 model with recent EIGEN-5C and EGM2008 geoid models proved that they are more precise in terms of spherical harmonic coefficients. In terms of spatial resolution, EGM2008 has an unprecedented resolution, because it is directly related to the higher order and degree of the model $(l=$ $m=2159$ ). The definition of model degree and order is important in determining the MDT, and results show that higher order models provide better MDT resolution and accuracy.

Recent geoid models (EIGEN-5C and EGM2008) have satisfactory results in determining MDT and currents, with precise identification of the main features of large and meso scales, which is not observed with EGM96. This fact confirms the improvements of recent models, in particular EGM2008 model, which holds higher degree and order than other models.

Problems related to noise have been solved with SSA filter application, with the advantage of easy and efficient application in lateral contours, and the suitable control through M matrix parameter.

Taking into account the whole South Atlantic, geostrophic currents resulting from MDT_EGM08 and MDT_EIGEN-5C models present higher correlation with hydrodynamic numerical model; BC was well characterized in all models, but with different resulting velocities.

Efforts focused on the use of geoid models in ocean surface circulation studies are easily justified by the facilities and advantages that satellite technology offers (spatial resolution, coverage, etc.). There are still many problems to solve, such as the analysis of current variations in time, by using data from altimeter satellites (TOPPEX/Poseidon, Jason-1 and Jason-2) referenced to geoid models.

In conclusion, the accomplished work confirms that GOCE system should significantly improve ocean circulation studies, mainly in shorter wavelengths, where present-day geoid models still require compatible resolution.

\section{REFERENCES}

ANDERSEN, B.; KNUDSEN P. The DNSC08 global Mean sea surface and Bathymetry, presented EGU2008, Vienna, Austria, 2008.

AVISO. Aviso user handbook merged TOPEX/POSEIDON products. AVI-NT- 02-101-CN 3, 1996.

BLECK, R. An oceanic general circulation model framed in hybrid isopycnic cartesian coordinates. Ocean Modell., v. 4, p. 55-58, 2002.

BÖEBEL, O.; DAVIS R. E.; OLLITRAUT M.; PETERSON R. G.; RICHARD P. L.; SCHMID C.; ZENK W. The intermediate depth circulation of the Western South Atlantic. Geophys. Res. Lett., v. 26, n.21, p. 33293332, 1999.

DESAI, S.; PICOT N.; CASE K.; VINCENT P. Aviso and podaac user handbook: IGDR and GDR jason products. Technical report, AVISO-CNES / PODAAC-NAS, 2003.

FÖRSTE, C. et al. EIGEN-GL05C - A new global combined high-resolution GRACE-based gravity field model of the GFZ-GRGS cooperation, presented EGU2008, Vienna, Austria, 2008.

GHIL, M., et al. Advanced spectral methods for climatic time series. Rev. Geophys., v. 40, n.1, 1003, doi:10.1029/2000RG000092, 2002.

KONDRASHOV, D.; GHIL M. Spatio-temporal filling of missing data in geophysical data sets. NPG-Nonlienar Processes in Geophysics, v. 13, 151-159, 2006.

LEMOINE, F. G. et al. The development of the joint NASA GSFC and the National Imagery and Mapping Agency (NIMA) Geopotential Model EGM96, Rep. NASA/TP1998-206861. Greenbelt, Md.: NASA Goddard Space Flight Cent., 1998.

MÜLLER, J. M.; IKEDA Y.; ZANGENBERG N.; NONATO L. V. Direct measurements of western boundary currents off Brazil between $20^{\circ} \mathrm{S}$ and $28^{\circ} \mathrm{S}, \mathrm{J}$. Geophys. Res., v. 103(C3), p. 5429-5437, 1998.

PAVLIS N. K.; HOLMES S.A.; KENYON S.C.; FACTOR J.K. An Earth gravitational model to degree 2160: EGM2008, presented EGU-2008, Vienna, Austria, 2008.

RAPP, R.; WANG Y. M.; PAVLIS N. The Ohio State 1991 geopotential and sea surface topography harmonic coefficient models. Rep 410, Department of Geodetic Science and Surveying, The Ohio State University, Columbus, 1991.

REID, J. L. On the total geostrophic circulation of the South Atlantic Ocean: flow patterns, tracers and transports. Prog. Oceanogr., v. 23, n. 3, p. 149-244, 1989.

RIO, M. H.; HERNANDEZ F. A mean dynamic topography computed over the world ocean from altimetry, in situ measurements, and a geoid model. J. Geophys. Res., v. 109, C12032, doi:10.1029/2003JC002226, 2004.

STRAMMA, L.; ENGLAND M. On the water masses and mean circulation of the South Atlantic Ocean. J. Geophys. Res., v. 104(C9), p. 20.863-20.883, 1999. 
SWENSON, S.; WAHR, J. Methods for inferring regional surface-mass anomalies form Gravity Recovery and Climate Experiment (GRACE) measurements of timevariable gravity. J.Geoph. Res., v. 107(B9), p. 2193, 2002.

TAPLEY, B. et al. GGM02-An improved Earth gravity field model from GRACE. J. Geod., v. 79, p. 467 - 478, doi:10.1007/s00190-005-0480-z, 2005.

VIANNA, M. L.; MENEZES V. V.; CHAMBERS D. P. A high resolution satellite-only GRACE-based mean dynamic topography of the South Atlantic Ocean, Geophys. Res. Lett., v. 34, L24604, doi:10.1029/2007GL031912, 2007.
WAHR, J.; MOLENAAR M.; BRYAN, F. Time variability of the Earth's gravity field: Hydrological and oceanic effects and their possible detection using GRACE. J. Geophys. Res., v. 103, 30,205-30,230, 1998.

(Manuscript received 19 February 2011; revised 16 August 2011; accepted 2 March 2012) 